\title{
presa bóveda de la Gougra
}

aprovechamientos hidroeléctricos, en rosario, del cantón

suizo de Valais

grupo de ingenieros suizos, en colaboración con el profesor A. Stuc

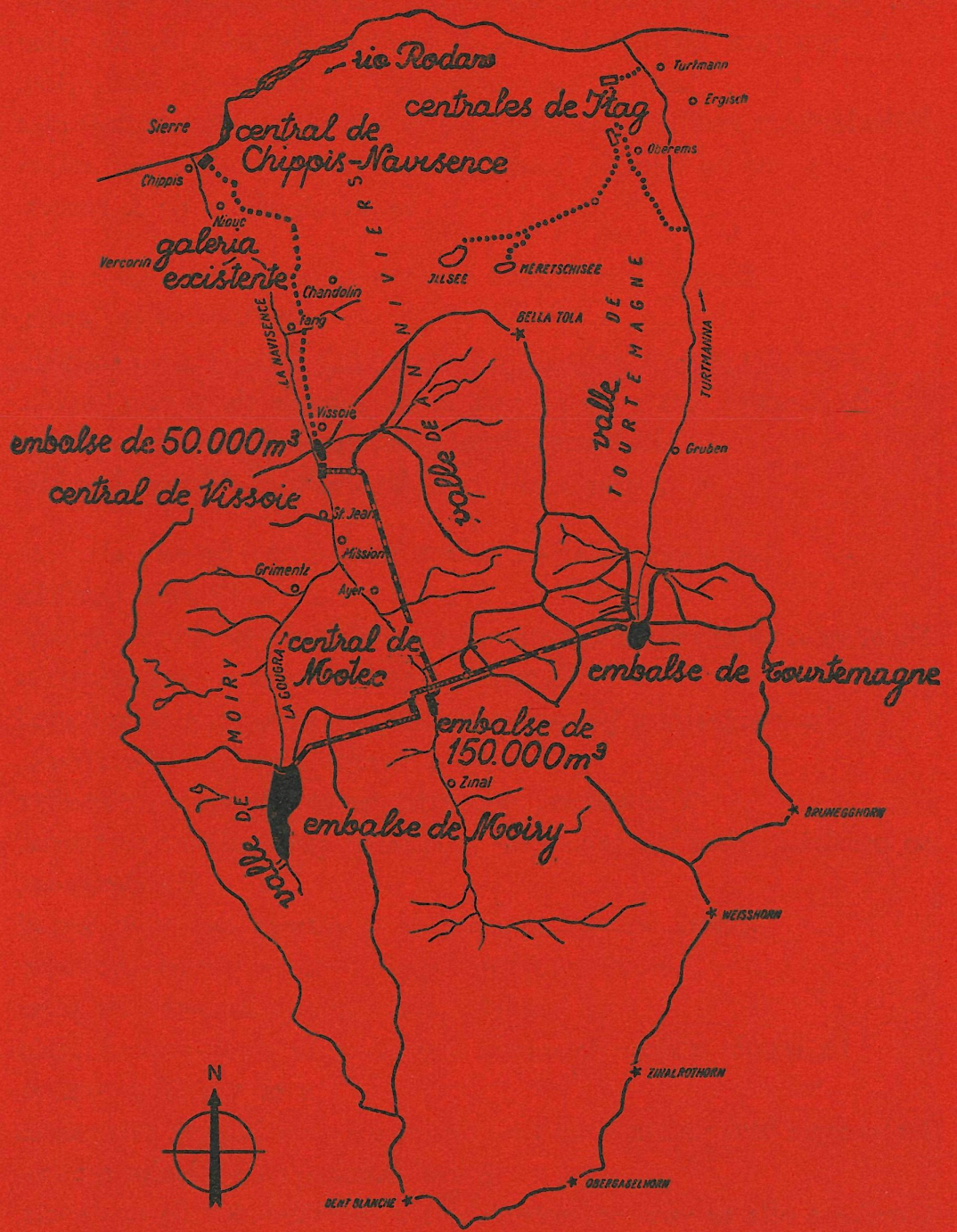

$5 \quad 2 \quad 4 \quad 8 \quad 0 \quad 10 \mathrm{~km}$

situación 
La guerra del hombre contra el agua es ya antigua.

Más de una humillación hubieron de sufrir nuestros lejanos antepasados, heroicos pioneros de la lucha por imponer la cultura

a la naturaleza.

Sus pequeños éxitos-incursiones atrevidas en el campo enemigo-

son para nosotros no sólo de incalculable valor técnico, sino

también merecedores de un tributo de admiración.

Ellos hicieron posible la realidad que hoy tenemos ante nuestros ojos

y que ha logrado transformarnos de sujetos a la naturaleza

en dominadores de la misma.

Porque aun cuando el agua ofrece todavía un campo inviolado y peligroso,

el hombre se ha enseñoreado ya casi totalmente de sus dominios,

y ha llegado incluso a encerrarla en campos de concentración.

Poderosos diques de contención impiden su fuga

y conservan sus energías a disposición del hombre.

Inútil es que el prisionero se debata e intente alcanzar

la libertad perdida.

Ya ni su viejo aliado de las olas, el viento, puede servirle de ayuda.

El fuerte dique se burla de sus esfuerzos

y las compuertas permanecen cerradas hasta que la voluntad

del vencedor disponga lo contrario.

Y entonces, inexorablemente, el líquido elemento se precipita sobre las palas que lo esperan para utilizar su fuerza.

Sus devaneos,

última resistencia antes de la entrega definitiva, son el reconocimiento supremo de la victoria humana.

El hombre, como experto luchador de judo,

ha sabido utilizar la misma fuerza de su rival, para dirigirla

a su propio provecho.

La energía hidroeléctrica es uno de los mayores botines alcanzados

por el hombre en su lucha secular.

Gracias a ella se ven incrementadas sus posibilidades de existencia,

al aumentar la producción,

su comodidad, sus facilidades de trabajo,

y al crear toda la enorme gama de instrumentos

de relación y dominio,

que le llevan a la progresiva conquista de posibilidades

que encierra todavía la naturaleza. 


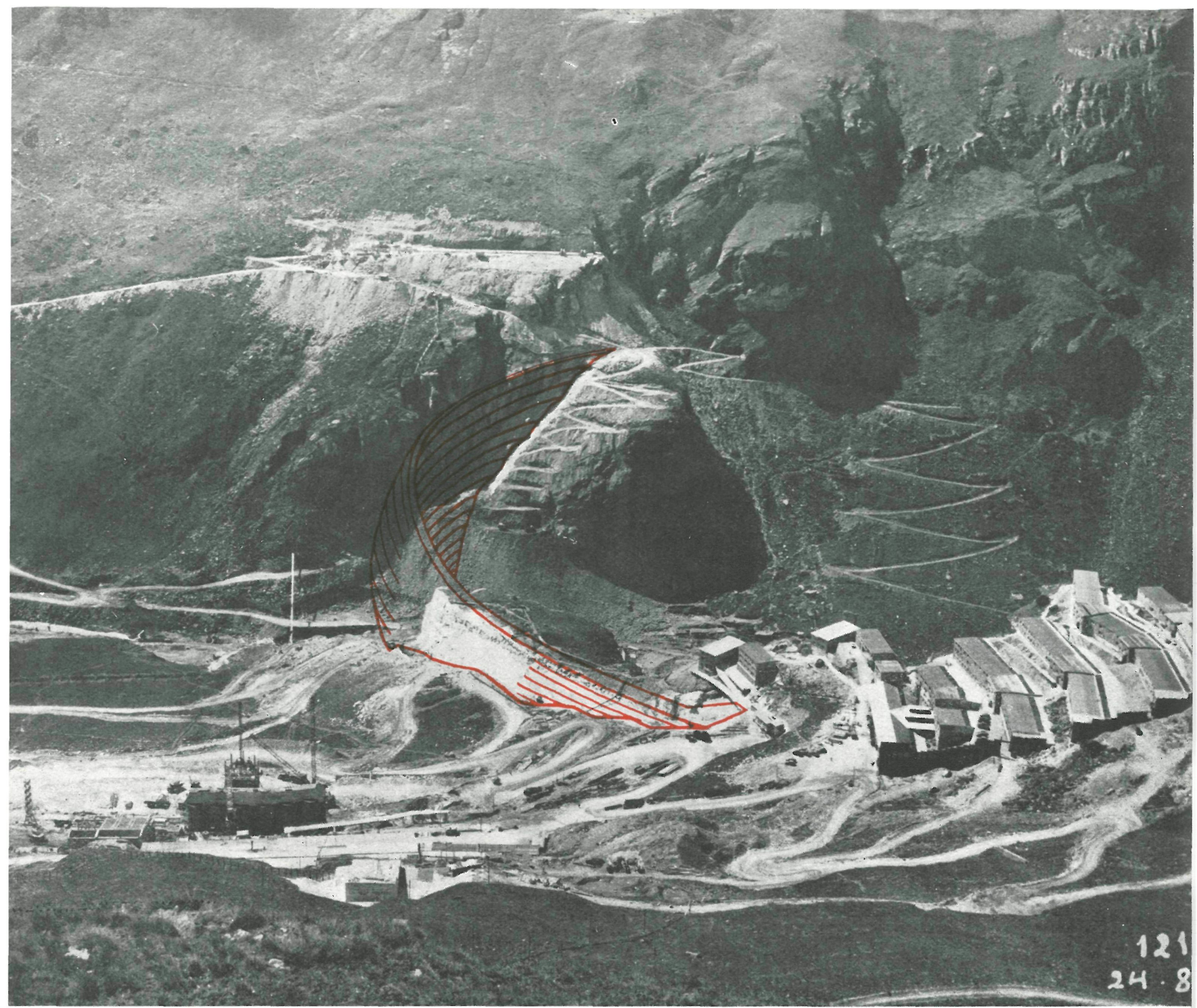

Para el aprovechamiento hidroeléctrico de la zona alpina, constituída por los valles formados por los ríos Navisence, la Gougra y el Tourtemagne, del cantón suizo de Valais, se ha redactado un proyecto general que coordina, y en su día explotará, las aguas que discurren por estos ríos antes de verter en el caudaloso Ródano. La sociedad concesionaria es Forces Motrices de la Gougra.

Las aguas del río Navisence se vienen aprovechando desde hace mucho tiempo, es decir, desde principios de este siglo, utilizando la central de Chippis-Navisence.

Posteriormente, y dadas las demandas de energía eléctrica, cada día crecientes, así como estudios más fundados y ambiciosos que se encaminaron para la revalorización de estas cuencas, se agruparon las empresas que se habían interesado anteriormente en este tipo de obras, para realizar un vasto proyecto general que aprovechará, racionalmente, estos caudales y desniveles, que se prestan a tal finalidad ventajosamente. 


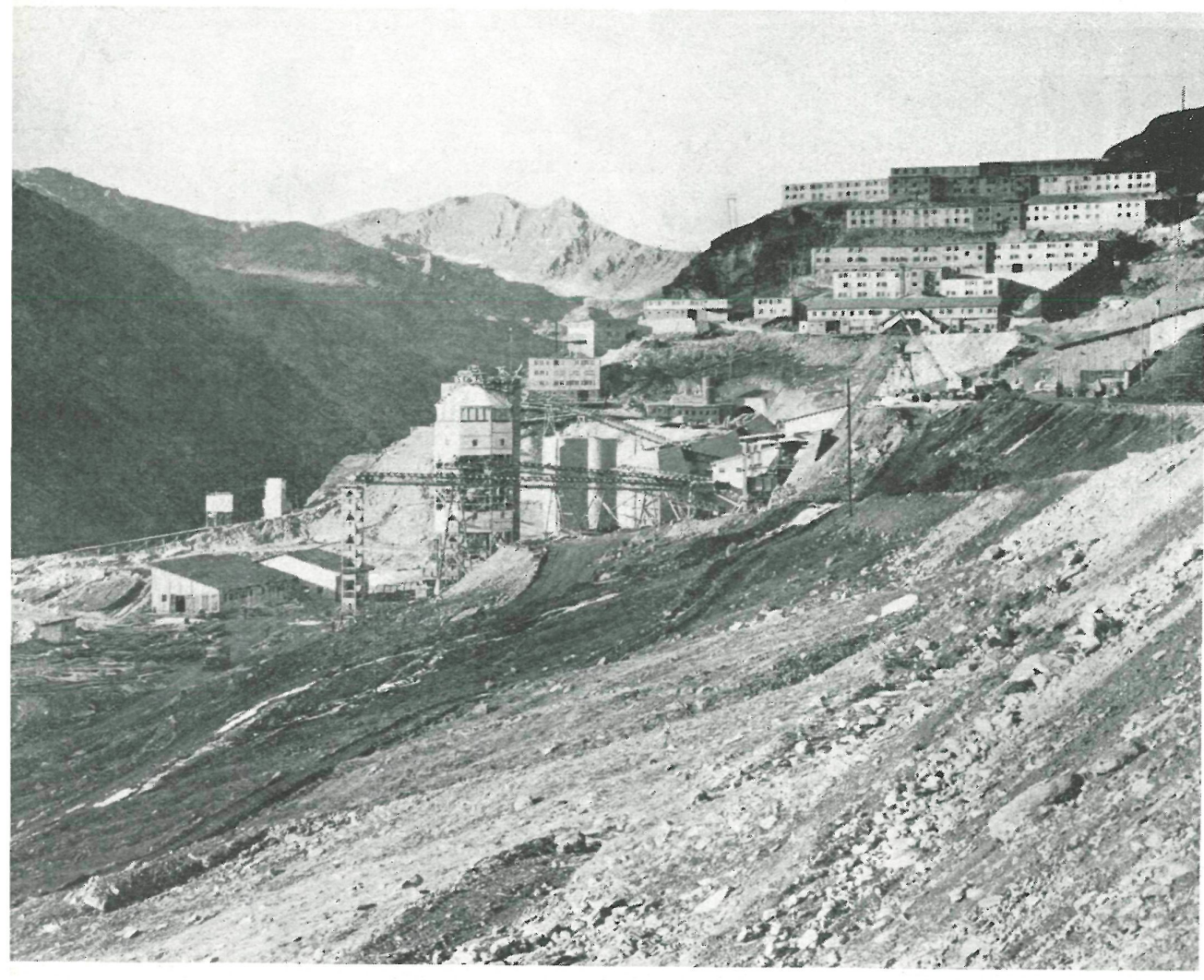

Instalaciones auxiliares

Central de hormigonado.

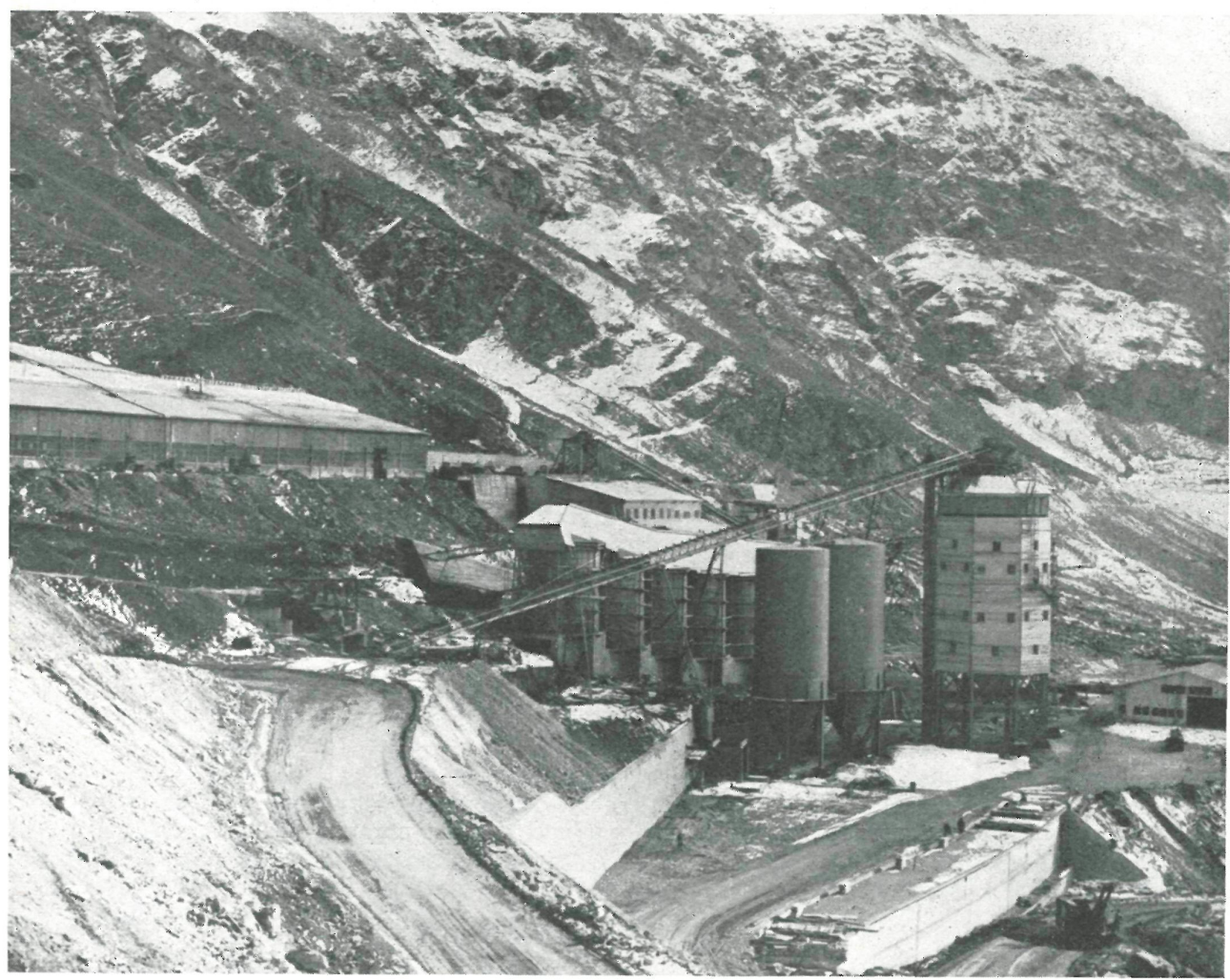

Como toda esta región alpina, las nieves, temperaturas y acusado relieve orográfico han constituído un tema de especial cuidado en la preparación y redacción del plan general de trabajos, particularmente en lo que se refiere a obras de acceso, campamentos para el personal, servicios auxiliares y abastecimiento de toda clase de materiales.

Teniendo en cuenta estas condiciones y accidentes locales de superficie, algunas tuberías en carga se han construído en subterráneo, ya que con ello se lograba mayor seguridad y permanencia.

\section{ideas generales sobre el proyecto en su conjunto}

En el curso superior del río la Gougra se está construyendo una presa-bóveda que formará un embalse de 72 millones de metros cúbicos. Las aguas aquí almacenadas se derivarán, a través de una galería sobre el valle del río Navisence, en el que se construirá la central, llamada Motec, y un embalse de compensación de unos 150.000 metros cúbicos de capacidad.

La superficie de las aguas del embalse de cabecera, denominado Moiry, se hallan a $2.246 \mathrm{~m}$ de altitud, y la central de Motec a 1.564; por tanto, dicho desnivel forma un salto de $682 \mathrm{~m}$, para el que se han instalado tres grupos generadores de $23.000 \mathrm{~kW}$ de potencia cada uno. Estos grupos son de eje horizontal, equipados con turbinas Pelton, de doble rodete, que giran a 750 r. p. m. y consumirán un caudal total de $12 \mathrm{~m}^{3} / \mathrm{s}$.

La cuenca del río Tourtemagne forma un embalse de unos $780.000 \mathrm{~m}^{3}$, de donde se derivarán las aguas, parcialmente, a la central de Motec, para ser bombeadas al embalse de Moiry con objeto de constituir una reserva durante los períodos de inactividad de la central de Motee

Este aprovechamiento, derivación y bombeo forman parte del primer escalón, de los tres en que se ha subdividido el plan conjunto de proyecto. 


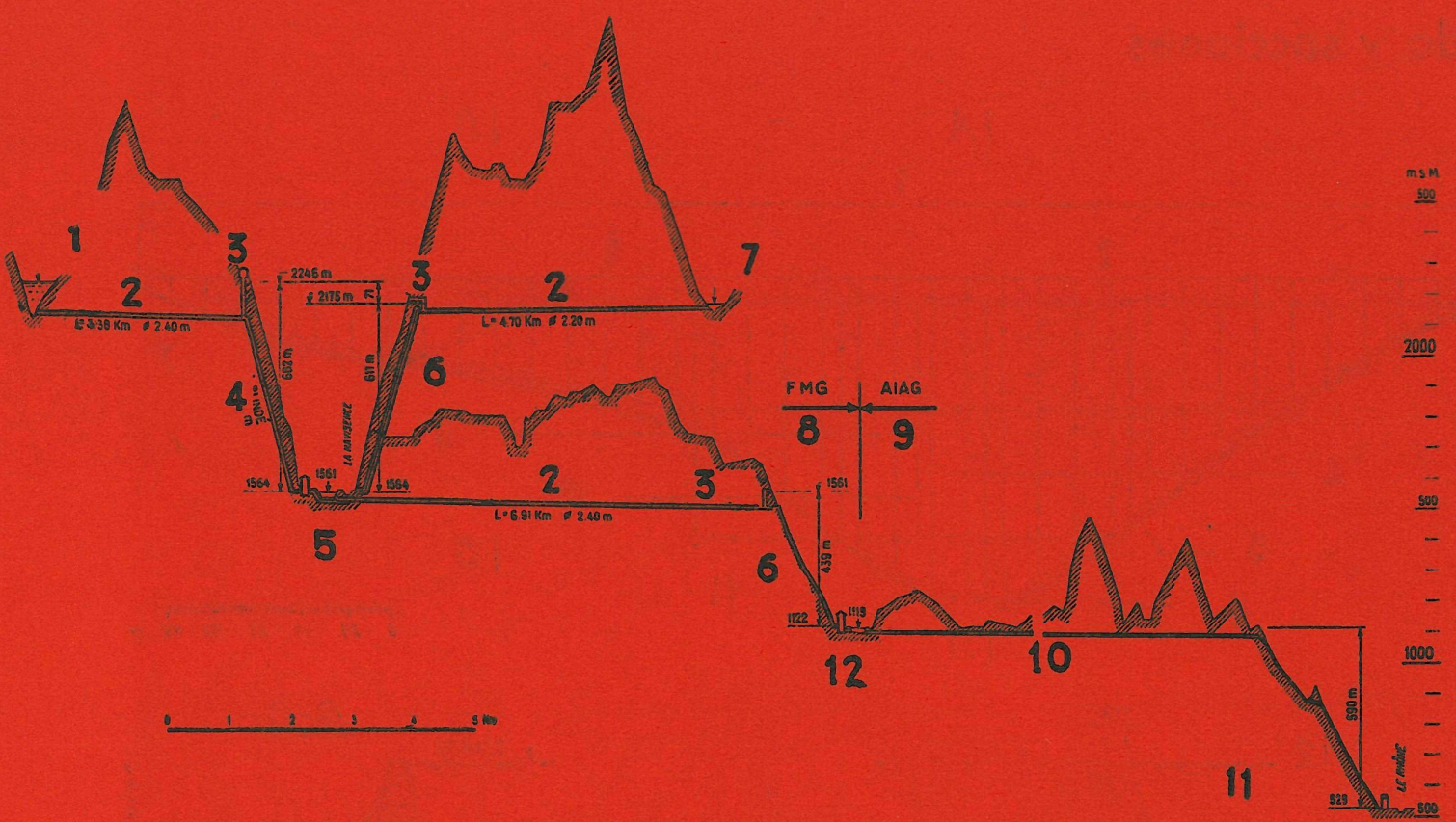

1. Embalse de Moiry: 72 millones de $\mathrm{m}^{3}$ de capacidad y $2.246 \mathrm{~m}$ de sititud.-2. Galeria.-3. Camara de equilibrio.-4. Chimenea en carga: de 1,5 a $1,7 \mathrm{~m}$ de diámetro.-5. Central de Motec: $69.000 \mathrm{~kW}$ de potencia.-6. Crimenea en carga: de 1,1 a $1,3 \mathrm{~m}$ de diametro.-7. Embalse de Tourtemagne: $780.000 \mathrm{~m}^{\circ}$ de capacidad.- 8 . Ln construccion.9. Existente. -10 . Galeria existente: $8,5 \mathrm{Km}$ de longitud.-11. Central existente de Chippis-Navisence: $50.000 \mathrm{~kW}$ de potencia.-12. Central de Vissoie: $45.000 \mathrm{~kW}$ de potencia instalada y $50.000 \mathrm{~m}^{3}$ de cuenco de compensación.

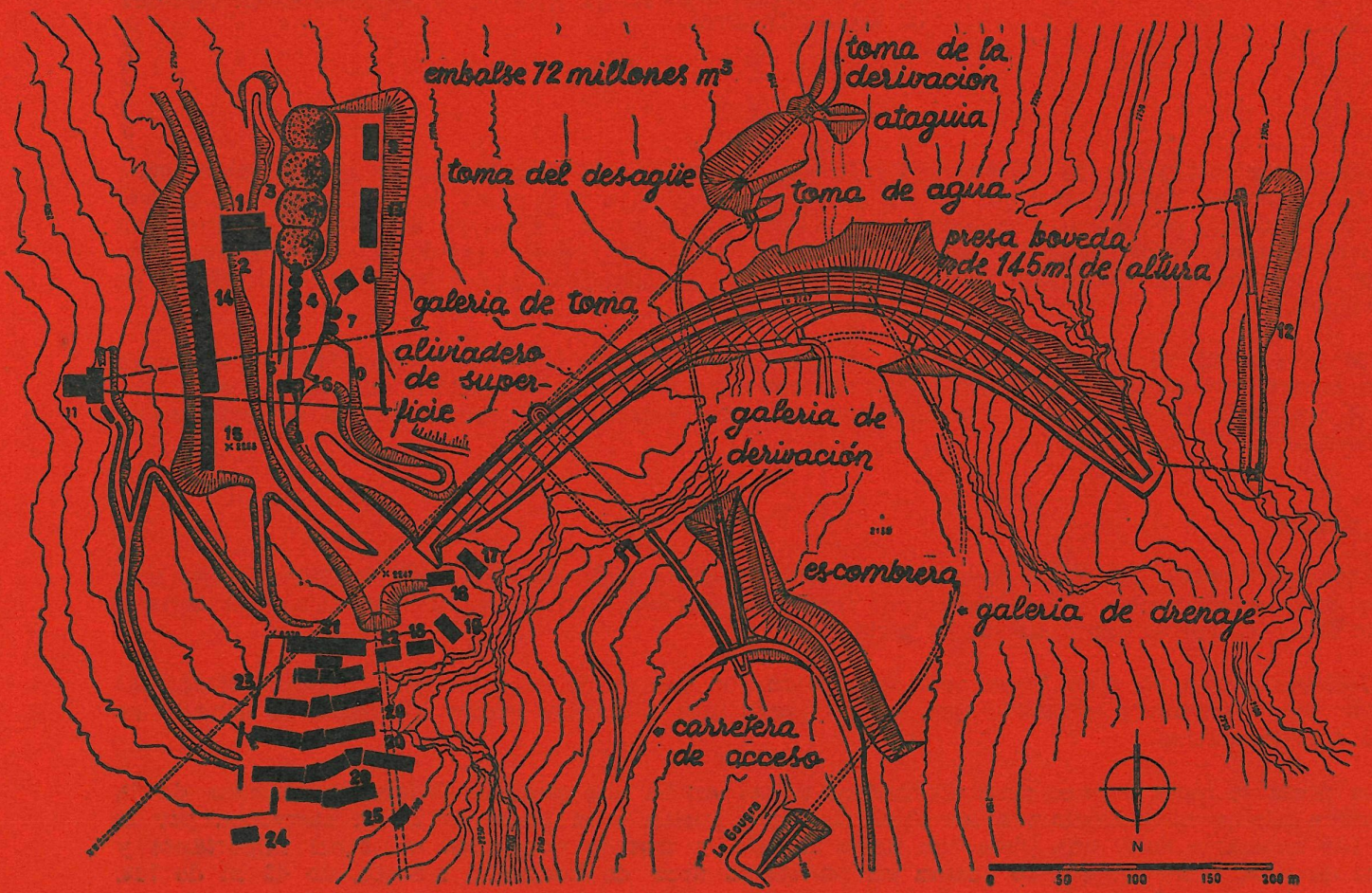




\section{alzado y secciones}

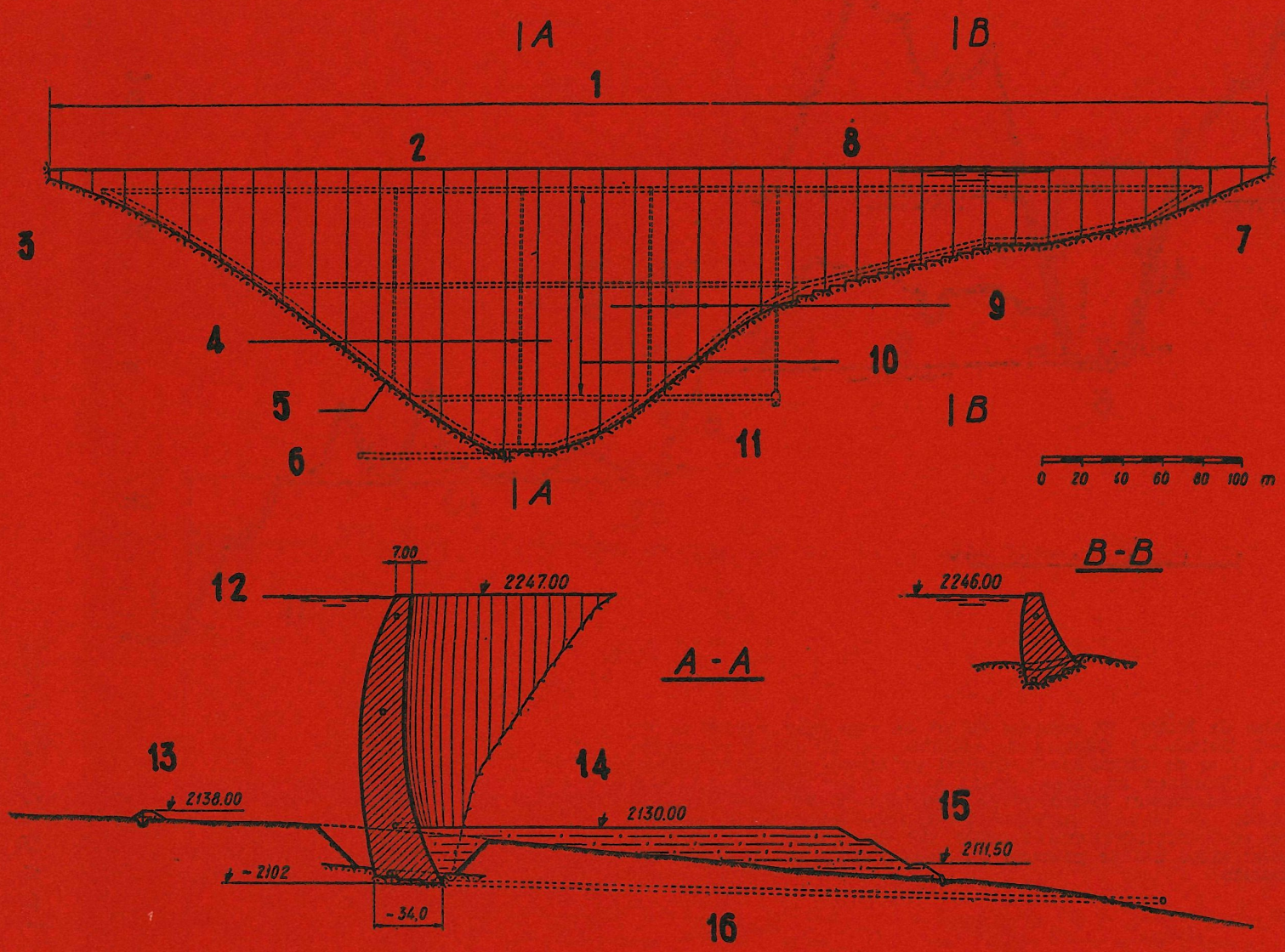

1. Longitud, $610 \mathrm{~m} .-2$. Cota, $2.247 \mathrm{~m} .-3$. Margen izquierda.-4. Pocillos, -5 . Roca. -6. Dren, -7 . Margen derecha, -8 . Nivel máximo, $2.246 \mathrm{~m}$. 9. Juntas de hormigonado.-10. Galenias de control. 11. Compuertas. de acceso -16 . Dren.

Las aguas restituidas de la central de Motec, asi como las del rio Navisence, cue las hace pasar un doble proceso desarenador, se las lleva, por una galería, a la cámara de equilibrio de la central de Vissoie, donde concurren también las aguas procedentes de la captación del arroyo Moulin. Este aprovechamiento forma un salto de $439 \mathrm{~m}$ de desnivel, constituye el segundo escalón del plan conjunto y contará con $45.000 \mathrm{~kW}$ de potencia instalada y un embalse de compensación de $50.000 \mathrm{~m}^{3}$ de capacidad.

De la central de Vissoie, y también por galeria, se recogen las aguas restituidas, que se llevan a la central de Chippis-Navisence, formando un salto de $590 \mathrm{~m}$ de desnivel y de $50.000 \mathrm{~kW}$ de potencia instalada. Este último tramo constituye el tercer escalón de proyecto general de explotación hidroeléctrica de esta cuenca.

La presa

Antes de empezar las obras de esta presa, situada en el valle de Moiry, se llevaron a cabo una serie de reconocimientos del subsuelo, por medio de sondeos, con objeto de determinar el terreno firme sobre el que se debia apoyar la presa.

Geológicamente, la roca firme está constituida por bancos de esquisto sano, cubierto tectónicamente por aluviones y arrastres que, en su parte más profunda, llegan a formar un espesor de unos treinta metros.

La presa se halla a unos cinco kilómetros aguas arriba del poblado Grimentz, término de 12 carretera alpina más próxima a las obras. De este pueblo a la presa no había carretera, por lo que fué necesario abrir una pista con firme robusto y trazado que salva un túnel importante obras de arte, entre las que se cuenta un puente en arco, de hormigón armado, de $42 \mathrm{~m}$ de luz. 


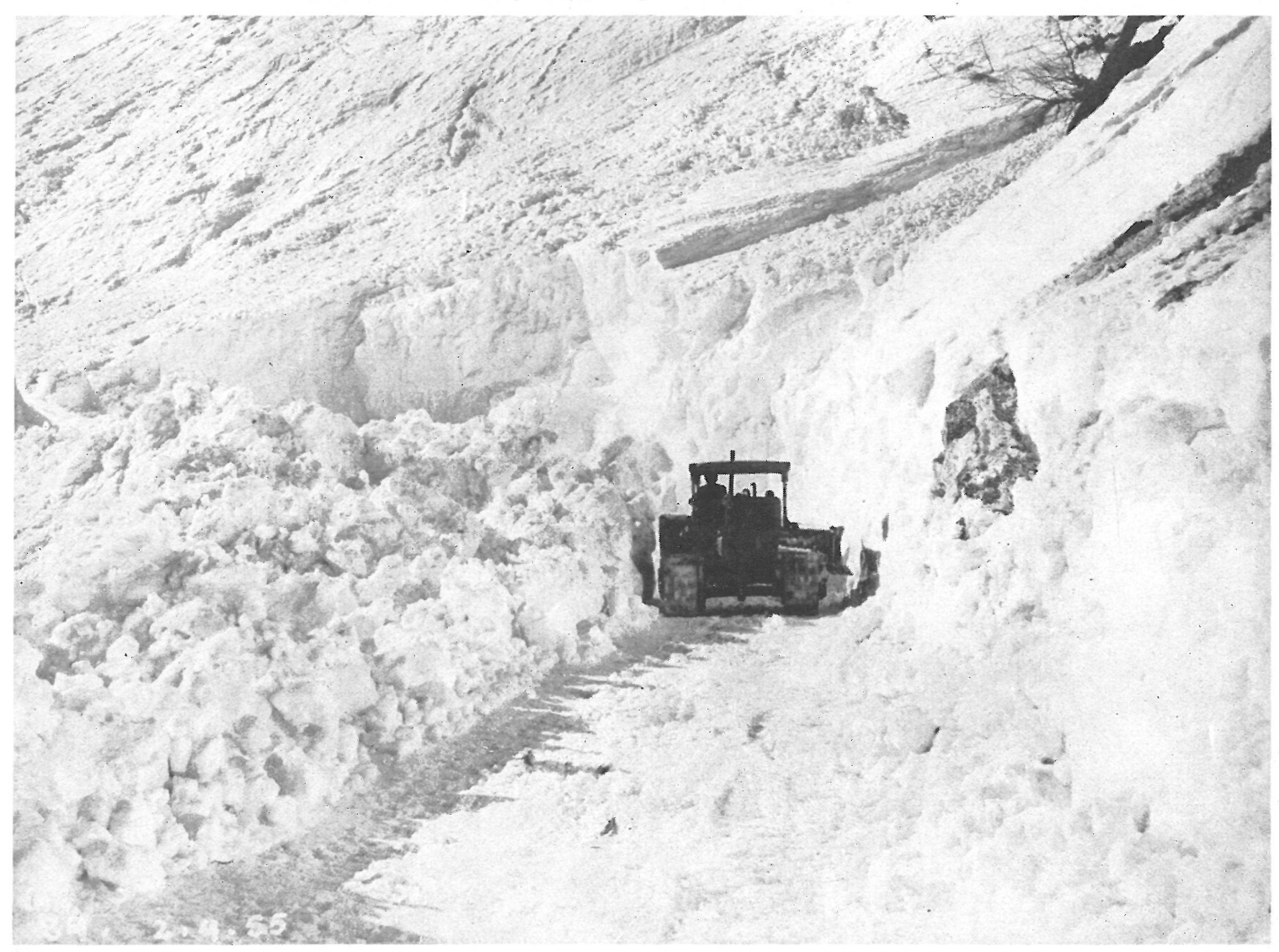

La derivación de aguas se realizó por medio de una galería de $2,40 \mathrm{~m}$ de diámetro, que vierte las aguas sobre un canal revestido de hormigón, construído a cielo abierto y con capacidad de desaguar $35 \mathrm{~m}^{3} / \mathrm{s}$ en régimen libre. Esta galería, una vez terminadas las obras, será utilizada como desagüe de fondo del embalse. Ađemás de esta galería, se ha construído otra que servirá para drenar las aguas que pudieran infiltrarse en cimientos. Con un nivel normal de aguas, el desagüe se puede hacer a razón de $50 \mathrm{~m}^{3} / \mathrm{s}$.

La presa, tipo bóveda, de $145 \mathrm{~m}$ de altura, se prolonga por uno de sus lados con un muro de ala de perfil presa gravedad; en coronación su desarrollo es de $610 \mathrm{~m}$ de longitud, y su espesor es variable, de cimientos a la parte superior, donde alcanza $7 \mathrm{~m}$, y 34 en el nivel de cimientos, que han sido objeto de una inyección de impermeabilización.

Los arcos horizontales tienen mayor espesor en arranques, con objeto de repartir mejor los esfuerzos sobre los estribos. El muro en ala tiene $200 \mathrm{~m}$ de longitud, uniéndose a la bóveda de tal forma, que se puedan absorber directamente los empujes que dan origen los arcos horizontales. En total se han empleado unos $800.000 \mathrm{~m}^{3}$ de hormigón para la construcción de la obra.

A fin de evitar la retracción en la medida de lo posible, la obra se ha subdividido en bloques de $16 \mathrm{~m}$ de longitud, y, además, se enfría el hormigón, artificialmente, por medio de una red de canalizaciones dejadas en el interior de la masa de hormigón, por la que circula agua fría. En cada junta entre bloques se ha dejado un pocillo vertical, que permite la alimentación de agua y facilita la inyección de las juntas. Los pocillos verticales se comunican entre sí por medio de galerías de visita, accesibles desde aguas abajo de la presa. 